\title{
Analysis of Modern Enterprise Employee Career Development Mode Innovation
}

\author{
Liqiong Wang \\ Business school, Xi'an International University, Xi'an Shaanxi, 710048, China
}

Keywords: Enterprise, Staff, Professional development model, Problem, Innovation strategy

\begin{abstract}
The modern enterprise pays more and more attention to employee career development, through innovative enterprise staff career development mode, can improve enterprise comprehensive strength, is advantageous to the enterprise and the interactive development of employees, which is more advantageous to match the employee's ability and the special requirements of jobs, improve the utilization efficiency of human resources. The connotation of career development and career development model, based on modern enterprise common employee career development are widespread problems, from the employee career development management, provide jobs trying to set up career development opportunities, information management system and build the career development as the guide of training incentive mechanism and so on to explore modern enterprise employee career development mode innovation.
\end{abstract}

\section{Introduction}

Human resource is the core of modern enterprise survival and development of resources is the first resource. How to human resources development, mining the potential efficiency and value of human resources, is the important index to evaluate the success or failure of the enterprise human resources management, also is the important influencing factors of success for enterprise management. Innovate enterprise staff career development pattern and promote the development of the enterprise, Employee career development as an important content of human resources development, increasingly more attention from enterprises.

\section{The connotation of professional development pattern}

Career development pattern means for most of the staff's career development process and the general description of the process of order form. This professional development mode is mainly for the division of employees in the professional development of different age stages. It is a general description of different types of professional development, is not for every employee in different age stages of career development. Each employee's personality development is different, some development fast, some slow development, some only limited to the development to a certain stage, some stay at some stage only a short time. And the improvement of the professional development model directly affects the career planning process, before the development of career planning and career management, therefore, to accurately locate the career development pattern.

\section{The problems existing of enterprises employee career development pattern}

\section{The widespread of enterprise selfish departmentalism.}

Career management is not only to achieve the development goals of the enterprise, also want to achieve the goals of employees in the personal development of the enterprise, both be short of one cannot, otherwise difficult to play the function to promote the development of enterprises. Now, a large of the issues hampering the enterprise development management is enterprise always with you as the core, has a serious selfish departmentalism, for career development in the process of the imbalance to the common development of the enterprise and the staff, focusing on enterprise's own development needs. 
Enterprise selfish departmentalism of widespread, make enterprise development regardless of personal interests and development goals, reduce the enthusiasm of the staff, make staff no longer care about enterprise's career development plans. This kind of behavior directly paralyzed trading mechanism between the employees and enterprises. Trading mechanism is changed, the original enterprise and employee contract relationship, make staff to work is no longer active, work efficiency and loyalty, turnover increased.

\section{Enterprise concepts in career development is old.}

In our country, a lot of enterprise management is not enough attention under the new era of career management theory. Most enterprises in the aspect of management still use traditional mode of human resource management, enterprise employees' personal development had not been enough attention. Some companies give employees, the rewards are limited to the material rewards, which didn't see the workers in a variety of needs of personal development, it is more impossible for employees in the true sense of the career development management.

\section{Diversity employee career path has not been established.}

Many small and medium-sized enterprises can't satisfy the employees' personal development needs. Employees within the organization and management level are inseparable, different management levels provide employees with opportunities for advancement and development platform is different. The characteristics of small and medium-sized enterprises are small scale, management level; this will affect the employees' development space. At the same time, many small and medium-sized enterprises also belong to the family management pattern, important or better positions have been family or relatives and friends, so that other employees no more development space.

\section{The innovation strategy of modern enterprise staff career development mode}

\section{Flexible management of enterprise staff career development.}

Career development strategy should make reasonable choice according to the employees in the different developing stages of the age and occupation. Employees of different ages have different requirements for career development, which requires the company formulate corresponding career development strategy. Career development has the following four stages:

The first stage for exploring stage, just enter society university graduates, for example, at the stage of career exploration, enterprise should help and guide them, they have to the enterprise and a correct positioning, determine your initial goal, familiar with the working environment as soon as possible, early out of the exploration.

The second stage to try stage, mainly refers to the staff at the age of 25 to 30.This part of the employee option periods of his life's direction, will continue to find suits own occupation. For this stage of the employees, to the right career development planning guidance to them, help them to find suitable for their jobs.

The third stage is the establishment of professional stage, mainly refers to the employees 30 to 45 years old. This part of the staff at an intermediate stage of career development, they are mainly middle managers and senior technical personnel, their professional status and career goals are basically stable, also have rich practical experience, can make a certain contribution to organization of the elite class. If they have a will continue to supply their knowledge, nutrients, improve their professional skills and comprehensive quality, performance management is used to promote their job performance. Second, expanding professional channel, so that they can have more promotion. 3 it is to take certain measures to keep their work enthusiasm, such as job rotation and improve the work content, play to their backbone. For up-and-coming employees to develop many kinds of promotion ways, let them have more opportunities to promotion and promotion.

The fourth stage for professional stable stage, age of the worker over the age of 45.Career this part of the staff, and gradually transition to retirement, to do their ideological work, training of successors, to arrange their career in the late stage. 


\section{Establish job change mechanism provides career chance to try.}

In this paper, mechanism of post changes including many, in addition to general staff rotating mechanism, including also make backup talents for exercise and making a middle management position, the enterprise can be in perfect conditions for expanding the scope of the blockbuster, choose the best talent as an important work.

One is that similar job rotation test.

It can choose two methods of vertical and horizontal rotation, lateral rotation is internally similar position on duty; longitudinal rotation refers to the same major in finance, engineering system on duty.

Second, the establishment of a mechanism of post exercise.

In college graduates just entering job, tend to have a 1-2 years post exercise period at the grass-roots level, although they work very hard during this period, but it can get a lot of experience and lessons, for their later work plays a very important role. During this period they can make the theory into practice, and the enterprise can through their performance in positions of discover and cultivate potential employees.

Third is competitive position to hire.

Enterprise on the number of senior positions is limited; many enterprises are now conducting middle management position competition system, and achieved some results. Under the conditions allow, more jobs could be included in the compete for jobs, such as long time vacancy and low performance appraisal of on-the-job personnel, enterprise need new job, etc., which can not only provide more competition opportunities to internal staff, also can promote the further improve their ability, inspire their enterprising, enterprises can also relieve some pressure of choose and employ persons through this system, guarantee the realization of the enterprise development goals and personal goals.

In a word, employee career development need to reasonable, perfect the internal flow of human resources system. Employees in the career development process, certain jobs change can let them learn more knowledge and skills, to build the foundation for the future development. As managers of enterprises, to allocate resources, staff to arrange them to suitable jobs, this does not increase the cost of choose and employ persons, also avoid the waste of human resources. Enterprise human resources management personnel according to the internal conditions and external conditions for constant exploration and innovation, improve the level of enterprise career management, through the staff to achieve the goals of individual to complete the overall development of the enterprise.

\section{To set up career development information management system.}

Professional information system is the foundation of organization career management, and staff in the career management, to understand the goals of the company at any time, enterprise culture and development strategy, pay particular attention to the human resource supply and demand and so on various aspects of information, in order to offer effective reference for future development, while the enterprise through the professional information system feedback and deal with all kinds of information. Good information system should be comprehensive response corporate jobs demand and supply situation of organization personnel, lay the foundation for the balance of supply and demand. According to the actual situation of the enterprise, the author thinks that, mainly involves the following aspects:

First, the vacancy information

Vacancies for employees, the business enterprise inside information is very important, open, multi-channel released vacancy information can provide a fair competitive environment for employees, for employees to see their development of hope in the future, to overcome the adverse impact of the company long-term accumulation due to network. For the company and the release of the competition that is timely and accurate information, attract more members to participate in the competition, can accurate reasonable evoked a good employee.

Second, to build employee electronic archives

The staff career embodies through the file. Implementation of employee career management, which is a need to insist for a long time and dynamic activity, and build a reasonable career 
development files, you can develop into mature management chain, for the employees provide clear development plan for the future development. Usually, if a company does not build up perfect staff information file system, position in a company need to be adjusted under the condition of the personnel, it will be difficult to timely and accurate understanding of employee information, reduce the efficiency of the personnel appointed, may also motivate the staff of slander. Therefore, developing company should build a systematic electronic to archive for the employees, fully understand and grasp the staff's pursuit, features, capabilities, and work performance, it is also a complete employee career management.

Third, effectively balance the relationship between the position demand and supply and employees.

If a vacancy in the normal operation of company, you need to supplement in time, to ensure that the enterprise operating normally. For employees to supply, you should to full consideration of relevant human resource policy, formulate reasonable recruitment range and policy. Need to give full consideration to the development of the enterprise, for staff career development planning, try to solve from the inside, maintain the stability of human relations, therefore, should be mainly from the internal employee promotion. Through to the employees within the company in the past experience and seniority, under the condition of the comprehensive consideration, the employee can be preferred. In this way, it can condense the enthusiasm of employees maintain the stability of employee turnover, and reserved for the future development of the enterprise culture and suitable to the position of the employee.

\section{Build up the guide training incentive mechanism for career development.}

To build up effective incentive mechanism in enterprises, it should be from the perspective of company employees, through the staff meet the practical need to motivate and arouse the enthusiasm of staff, make staff development will be more suitable for company. As two of the most main incentive ways and means of compensation and career development has been widely adopted in many companies. However, most companies are through the design perfect and scientific compensation system to motivate the enthusiasm of employees, there are few companies with the excellent design of staff career development to inspire staff enthusiasm.

Enterprises and companies to professional development as a means of effective incentive, it is able to play an immeasurable role in the development of enterprises. How to build the professional development of incentive mechanism, from the view of innovation is needed to build a career oriented to continue education and training, in particular can be done from the following:

First, although the position and job promotion is an effective means of incentive, but in normal management should also be used in other career development incentives, such as job rotation, the important responsibility of the service, the creation of various training and continuing education opportunities, and so on. In Taiyuan iron and steel group's career incentives, for example, the company on the basis of full respect for employees, understanding employees, as far as possible provide more training opportunities for staff, talents from the excellent staff, to the well-known colleges and universities for further study.

Second, the company make plans for the enterprise staff's career development, which should consider all aspects of staff quality, such as the staff's professional skills, management level and professional ethics, and so on. If in the promotion process, only pay attention to the employee's work performance, will cause promoted the wrong decision, may result in not suitable for management of outstanding business personnel engaged in management job, brings to the enterprise's development obstacle, also makes good business people lost better post exercise opportunity.

Third, for staff career planning, want to choose the appropriate rhythm. Some enterprises in selecting staff how to appear on the speed is not appropriate, which often brings bad influence to the enterprise and employees themselves. The fast pace of ascension, for example, can lead to the development of employees lost after reaching the top space and negative, and slower pace of ascension will lead to employees cannot effectively improve their own knowledge and ability, cannot get effective psychological motivation. Therefore, the enterprise should have a plan when improve 
employees have a principle, make each employee in 2-4 years there is a promotion, improve employee's self-identity, and study for the next station to provide a reasonable platform.

\section{References}

[1] Luo Hong-mei. Enterprise staff career development channel research. Jiangsu university,2006.

[2] Wang Zuogong. The six key steps of employee career development management of. Chinese labor, 2006, 02:54-56.

[3] Huang Wenyan, Xie Yuhua. Telecom enterprise staff career development planning and incentive mechanism and its application. Journal of Changsha vocational and technical college of communication, 2006, 02:1-4.

[4] Yin Zheng-gang. Employee career development research. Journal of Henan institute of education (philosophy and social science edition), 2004, 01:71-73.

[5] Lin Jinfeng. Hotel staff career development path and influencing factors of research. South China university of technology, 2011.

[6] Liu Lingling. The necessity of the current our country enterprise employee career development management and countermeasures study. Journal of Chongqing institute of technology, 2001, 04:26-28+31. 